\title{
Efficient conversion of phytosterols into 4-androstene-3,17-dione and its C1,2-dehydrogenized and 9a-hydroxylated derivatives by engineered Mycobacteria
}

Xin $\mathrm{Li}^{1 \dagger}$, Tian Chen ${ }^{1 \dagger}$, Fei Peng ${ }^{1 \dagger}$, Shikui Song ${ }^{1}$, Jingpeng Yu', Douanla Njimeli Sidoine ${ }^{1}$, Xiyao Cheng ${ }^{1}$, Yongqi Huang ${ }^{1}$, Yijun $\mathrm{He}^{2^{*}}$ and Zhengding $\mathrm{Su}^{1 *}$

\begin{abstract}
4-Androstene-3,17-dione (4-AD), 1,4-androstadiene-3,17-dione (ADD) and 9a-hydroxyl-4-androstene-3,17-dione (9OH-AD), which are important starting compounds for the synthesis of steroidal medicines, can be biosynthetically transformed from phytosterols by Mycobacterium strains. Genomic and metabolic analyses have revealed that currently available 4-AD-producing strains maintain the ability to convert 4-AD to ADD and 9OH-AD via 3-ketosteroid1,2-dehydrogenase (KstD) and 3-ketosteroid-9a-hydroxylase (Ksh), not only lowering the production yield of 4-AD but also hampering its purification refinement. Additionally, these 4-AD industrial strains are excellent model strains to construct ADD- and 9OH-AD-producing strains. We recently found that Mycobacterium neoaurum HGMS2, a 4-AD-producing strain, harbored fewer kstd and ksh genes through whole-genomic and enzymatic analyses, compared with other strains (Wang et al. in Microbial Cell Fact 19:187, 2020). In this study, we attempted to construct an efficient 4-AD-producing strain by knocking out the kstd and ksh genes from the M. neoaurum HGMS2 strain. Next, we used kstd- and ksh-default HGMS2 mutants as templates to construct ADD- and 9OH-AD-producing strains by knocking in active kstd and ksh genes, respectively. We found that after knocking out its endogenous kstd and ksh genes, one of these knockout mutants, HGMS2 ${ }^{\Delta k s t d 211+\Delta k s h B 122}$, showed a 20\% increase in the rate of phytosterol to 4-AD conversion, compared relative to the wild-type strain and an increase in 4-AD yield to $38.3 \mathrm{~g} / \mathrm{L}$ in pilot-scale fermentation. Furthermore, we obtained the ADD- and 9OH-AD-producing strains, HGMS2 ${ }^{\text {kstd2 } 2+\Delta k s t d 211+\Delta k s h B 122}$ and HGMS2 ${ }^{k s h A 51+\Delta k s t d 211+\Delta k s h A 226}$, by knocking in heterogenous active kstd and ksh genes to selected HGMS2 mutants, respectively. During pilot-scale fermentation, the conversion rates of the ADD- and 9OH-AD-producing mutants transforming phytosterol were 42.5 and $40.3 \%$, respectively, and their yields reached 34.2 and $37.3 \mathrm{~g} / \mathrm{L}$, respectively. Overall, our study provides efficient strains for the production of 4-AD, ADD and 9OH-AD for the pharmaceutical industry and provides insights into the metabolic engineering of the HGMS2 strain to produce other important steroidal compounds.
\end{abstract}

*Correspondence: heyijun@gotochem.com; zhengdingsu@hbut.edu.cn

'Xin Li, Tian Chen and Fei Peng contributed equally to this work

${ }^{1}$ Key Laboratory of Industrial Fermentation (Ministry of Education),

National "111"Center for Cellular Regulation and Molecular Pharmaceutics

and Hubei Key Laboratory of Industrial Microbiology, Hubei University

of Technology, Wuhan 430068, China

${ }^{2}$ Hubei Goto Biotech Inc., No. 1 Baiguoshu Road, Shuidu Industrial Park,

Danjiangkou 442700, Hubei, China permits use, sharing, adaptation, distribution and reproduction in any medium or format, as long as you give appropriate credit to the original author(s) and the source, provide a link to the Creative Commons licence, and indicate if changes were made. The images or other third party material in this article are included in the article's Creative Commons licence, unless indicated otherwise in a credit line to the material. If material is not included in the article's Creative Commons licence and your intended use is not permitted by statutory regulation or exceeds the permitted use, you will need to obtain permission directly from the copyright holder. To view a copy of this licence, visit http://creativecommons.org/licenses/by/4.0/. The Creative Commons Public Domain Dedication waiver (http://creativeco mmons.org/publicdomain/zero/1.0/) applies to the data made available in this article, unless otherwise stated in a credit line to the data. 
Keywords: 1,4-Androstadiene-3,17-dione (ADD), 21-Hydroxy-20-methylpregn-4-en-3-one (BA), 3-Ketosteroid1,2-dehydrogenase (KstD), 3-Ketosteroid-9a-hydroxylase (Ksh), 4-Androstene-3,17-dione (4-AD), 9a-Hydroxyl-4androstene-3,17-dione (9OH-AD), Mycobacterium sp. strain

\section{Introduction}

Steroids are widely used as antibacterial, anti-inflammatory, antiviral and anticancer therapeutics $[1,2]$. The core structure of steroids consists of three six-member cyclohexane rings and one five-member cyclopentane ring. 4-Androstene-3,17-dione (4-AD), 1,4-androstadiene-3,17-dione (ADD) and 9 $\alpha$-hydroxyandrost-4ene-3,17-dione (9OH-AD) are the most important starting materials for the synthesis of advanced steroid compounds. Accordingly, these three compounds are in high demanded by the pharmaceutical industry $[3,4]$. The bioconversion of phytosterol to 4-AD, which is an important process in the pharmaceutical industry, uses bacteria that harbor partial steroid-degrading pathways $[5,6]$. Although many microbes such as Pseudomonas sp. NCIB 10590 [7] and Nocardioides simplex VKM Ac-2033D $[2,8]$ contain steroid-degrading pathways, only strains from the Mycobacterium genus can efficiently accumulate 4-AD for potential industrial application $[1,3,9,10]$. Mycobacterium neoaurum NRRL B-3805 was the first strain that was used to industrially transform phytosterol to 4-AD via its incomplete steroid-degrading pathways $[11,12]$. Since then, other mycobacterial strains with the potential industrial application in the biotransformation of phytosterol to 4-AD, have been identified, including Mycobacterium sp. NwIB-01 [10]. Nevertheless, the accumulation of 4-AD in currently available industrial 4-AD-producing strains is often accompanied by the occurrence of ADD, 9OH-AD and other 4-AD derivatives generated during phytosterol transformation $[1$, 4]. The presence of these 4-AD derivates not only hampers the 4-AD purification and refining process but also significantly reduces 4-AD yield. However, no effective ADD- and 9OH-AD-producing strains are currently available for industrial-scale application.

Biochemical and genomic investigations have revealed that all steroid-degrading bacteria share a core pathway via 9,10-secosteroid intermediates that participate in the breakdown of steroid ring structures [13, 14]. The conversion of phytosterol to 4-AD involves 11 enzymes in 14 consecutive enzymatic steps that must occurs before $4-\mathrm{AD}$ can be completely degraded $[15,16]$. Therefore, 4-AD can be considered a catabolic intermediate in the phytosterol-degrading pathway and a precursor of 9,10-secosteroid intermediate. Two enzymes, 3-ketosteroid-1,2-dehydrogenase (KstD) and 3-ketosteroid $9 \alpha$-hydroxylase (Ksh), are responsible for the rupture of the 4-AD ring at the $\mathrm{C} 9,10$-position. This leads to the formation of 3-hydroxy-9,10-secoandrost-1,3,5(10)-triene9,17-dione (HSA), which is readily catabolized to $\mathrm{CO}_{2}$ and $\mathrm{H}_{2} \mathrm{O}$ [17-19].

Reducing KstD and Ksh activities in 4-AD-producing strains has been shown to prevent the ring opening of steroidal intermediates and improve the accumulation of 4-AD, ADD and 9OH-AD during phytosterol transformation [20-32]. Traditional mutation approaches including ultra-violet light and chemical-mediated mutation have been employed to improve the productivity of 4-AD and other sterol compounds [33-39]. Owning to progress in the genome sequencing of sterol degradation strains, recent studies have focused on engineering highly efficient phytosterol-transforming strains using gene and metabolic engineering. Knockout of the cas $C$ gene from Rhodococcus jostii RHA1 resulted in the accumulation of a 5-carbon side chain cholate metabolite [40]. Additionally, depletion of the $c h o D, h s d D$ and $k s t D$ genes in M. smegmatis vaccae enhanced the accumulation of 9OH-AD [33]. Knockout of the kstd gene from the M. neoaurum NwIB-01 strain increased AD and ADD production [10], while knockout of the kstd genes from M. neoaurum ATCC25795 harboring highly active Ksh enzymes led to the accumulation of $9 \mathrm{OH}-\mathrm{AD}[23,30]$. However, to the best of our knowledge, these strains have not been reported for industrial application because of the existence of multiple and even unknown KstD and Ksh enzymes in these strains.

KstD is a flavin adenine dinucleotide (FAD)-dependent enzyme that introduces a double bond at the position between the $\mathrm{C} 1$ and $\mathrm{C} 2$ atoms of the A-ring of 3-ketosteroid substrates including 4-AD and 9OH-AD [41]. A bioinformatic study revealed that KstD enzymes exist in more than 500 different microbes, especially in bacteria belonging to the phylum Actinobacteria [41]. Moreover, a single species may contain multiple KstDs that are substrate specific. For instance, Rhizobium sp. strain [42], M. neoaurum DSM 1381 [43, 44] and Gordonia neofelifaecis NRRL B-59395 [45] carry at least three different KstD enzymes, each of which exhibits unique features in terms of its amino acid sequence, three-dimensional conformational structure and substrate specificity. Ksh is a two-component iron-sulfur monooxygenase that consists of the oxygenase KshA and the reductase KshB. The Ksh homologues are distributed over several phylogenetic groups [46]. For example, Mycobacterium sp. VKM 
Ac-1817D effectively transforms phytosterol into 9OH$\mathrm{AD}$ using five KshAs and two KshBs [47]. Additionally, $R$. rhodochrous DSM43269 contains five KshA homologues, each of which exhibits distinct specificity for different substrates [48-50]. Many putative $k s h$ genes have been identified in currently available 4-AD-producing strains $[10,51]$. The balance between the accumulation of 4-AD and the inhibition of 4-AD degradation during phytosterol fermentation is managed by controlling the fermentation time. However, it is difficult to control this balance during prolonged fermentation processes, which often results in unstable conversion yield $[16,52]$. This drawback becomes even worse when phytosterol fermentation is conducted in an aqueous medium [53, 54]. Accordingly, it is essential that an ideal 4-AD producing strain lacks all KstD and Ksh activities for industrial application.

We recently characterized a 4-AD producing strain, Mycobacterium neoaurum HGMS2, using genomic analysis and found it contained less kstd and ksh genes than other investigated strains. Specifically, the genome of the HGMS2 strain contains one kstd gene (kstd211), two $k s h A$ genes (kshA226 and $k s h A 395)$ and one $k s h B$ gene (kshB122) [55]. The enzymes encoded by these genes, KstD211, KshA226, KshA395 and KshB122, are relevant to the generation of 4-ADD and $9 \mathrm{OH}-\mathrm{AD}$ and the degradation of 4-AD during phytosterol fermentation (Fig. 1). In this study, we investigated the effects of these four genes on the accumulation of 4-AD during phytosterol transformation, using a homologous recombination approach, with the goal of providing efficient 4-AD-, $\mathrm{ADD}$ - and 9OH-AD-producing strains for industrial application. Knockout of the kstd211 and kshB122 genes from the HGMS2 strain abolished the accumulation of $\mathrm{ADD}$ and $9 \mathrm{OH}-\mathrm{AD}$ and significantly improved the conversion yield of 4-AD compared with that of the wildtype strain. Furthermore, we knocked in heterogenous active kstd or ksh genes to selected HGMS2 mutants to generate $\mathrm{ADD}$ - and 9OH-AD-producing strains. As a result, our study work provided a high-efficiency 4-ADproducing bacterial strain and also provides ADD- and $9 \mathrm{OH}-\mathrm{AD}$-producing strains with potential application in the pharmaceutical industry.

\section{Materials and methods Materials}

A DNA gel extraction kit was purchased from Omega Biotek (Hubei, China). Other molecular biology reagents were of the highest grade and were obtained from Thermo Scientific (Shanghai, China). 4-Androstene3,17-dione (4-AD), 1,4-androstene-3,17-dione (ADD), $9 \alpha$-hydroxyl-4-androstene-3,17-dione (9OH-AD), 21-hydroxy-20-methylpregn-4-en-3-one (BA) and phytosterol were obtained from Hubei Goto Pharmaceutical Co. (Xiangyang, China). In this study, the purity of phytosterol obtained from commercial source was $95 \%$ on average and typically, composed of $\beta$-sitosterol (47.5\%, $\mathrm{MW}=414.71 \mathrm{Da})$, campesterol $(26.4 \%, \mathrm{MW}=402.7 \mathrm{Da})$, stigmasterol $(17.7 \%, \mathrm{MW}=412.69 \mathrm{Da})$ and brassicasterol $(3.6 \%, \mathrm{MW}=398.66 \mathrm{Da})$ and so that an average of molecular weight of $410.40 \mathrm{Da}$. Phenazine methosulfate (PMS, 99\%) and nitro blue tetrazolium with purities of $99 \%$ were purchased from Sigma-Aldrich (Shanghai, China).

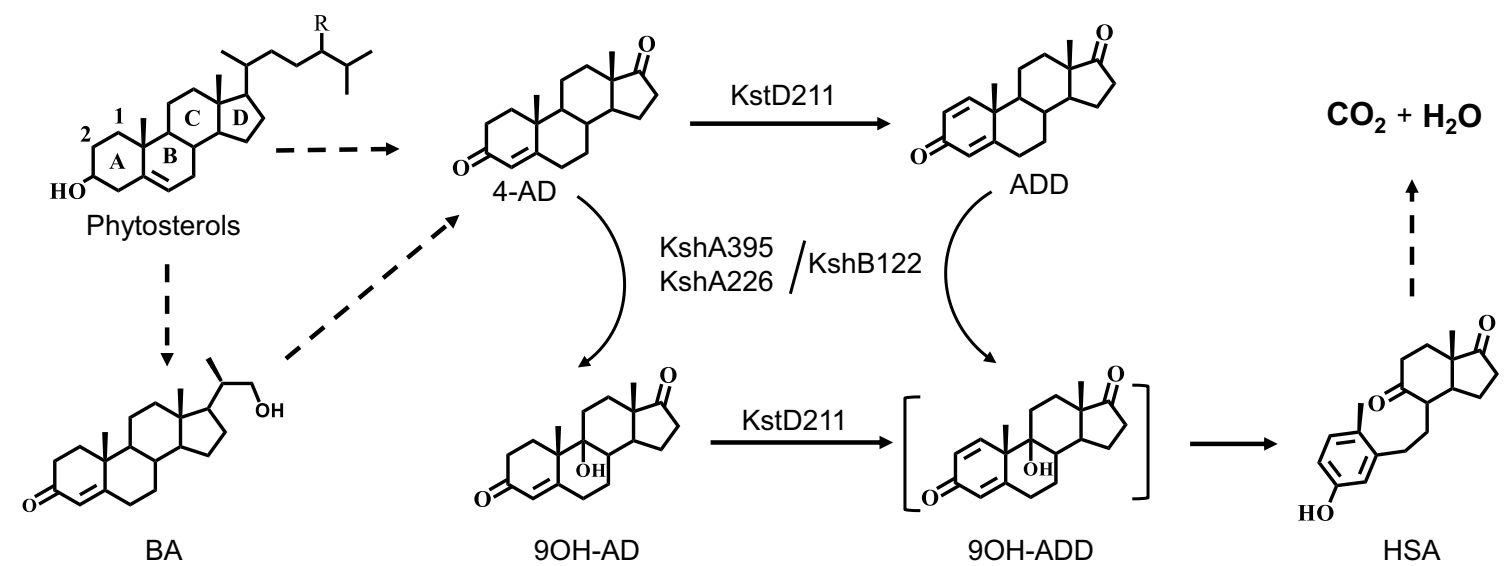

Fig. 1 KstD and Ksh enzymes are responsible for 4-AD accumulation and its degradation during phytosterol catabolism in M. neoaurum HGMS2. The steroidal core structure contains four rings, namely, rings A, B, C, and D, labeled on phytosterol. Successive steps involve the formation of $9 a-h$ ydroxy-1,4-androstadiene-3,17-dione ( $9 \mathrm{OH}-\mathrm{ADD})$, which is a transient intermediate and simultaneously converts to 3-hydroxy-9,10-secoandr ost-1,3,5(10)-triene-9,17-dione (HSA). 4-AD: 4-androstene-3,17-dione; ADD: 1,4-androstadiene-3,17-dione; 9OH-AD: 9a-hydroxy-4-androstene-3,17-d ione and BA: 21-hydroxy-20-methylpregn-4-en-3-one 
Restriction enzymes, dNTPs, and Taq polymerase were purchased from TaKaRa Co. (Dalian, China).

Bacterial strains, plasmids, DNA extraction and purification Mycobacterium neoaurum HGMS2, a non-pathogenic industrial Mycobacterium, was maintained in our laboratory and deposited at China Center for Type Culture Collection (CCTCC No: M2012522) [55] and its genome sequence was deposited in GenBank (CP031414.1). The plasmids p2NIL (Cat. 20188) [56] and pT18mobsacB (Cat. 72648) were purchased from AddGene (Watertown, MA, USA).

The genomic DNAs of Mycobacterium sp. HGMS2 and its mutants were extracted using a Bacterial Genomic DNA Extraction Kit from Tiangen (Beijing, China). Plasmids were purified using a Plasmid Purification Kit from Tiangen (Beijing, China). PCR fragments were purified using an agarose gel purification kit (Qiagen, USA).

\section{Construction of homogenous recombinant vectors and knockout and knockin experiment}

The pT18mobsacB was used as a template to amplify the sucrose lethality gene $S a c B$ that was originally from Bacillus subtilis 168. SacB and its promotor and terminator were amplified by PCR using two primers (sacB$\mathrm{F}$ and sacB-R) that introduced EcoRI sites at both ends. The nucleotide sequences of sacB-F and sacB-R were 5'-CCGGAATTCCACATATACCTGCCGTTC-3' and 5'-CCGGAATTCTTATTTGTTAACTGTTAATTGT-3', respectively. The PCR fragment and the p2NIL plasmid were individually digested with the EcoRI restriction enzyme. The SacB fragment and the restriction plasmid were recovered by agarose gel purification. Digested $S a c B$ DNA fragment was subcloned into the digested p2NIL plasmid by T4 DNA ligase, and the resultant plasmid was named p2NILSac.

To knock out the kstd and ksh genes from the HGMS2 genome, each of these genes was replaced through homologous recombination with a specific DNA fragment that contained the upstream sequence and the downstream sequence outside of the targeted gene. Each upstream sequence and each downstream sequence were approximately $1 \mathrm{kbp}$ in length. The upstream sequence and the downstream sequence of each target gene were amplified from the HGMS2 genome (Additional file 1: Table S1) using two pairs of primers (Additional file 1: Table S2). The amplified upstream sequence and downstream sequence for each target gene were digested with two pairs of restriction enzymes, BamHI/XbaI and $\mathrm{XbaI} /$ HindIII, respectively. Digested fragments were ligated into the p2NILSac vector that was predigested with BamH I/HindIII. The ligated plasmids were transformed into $E$. coli DH5a competent cells for amplification. Constructed plasmids were confirmed by DNA sequencing.

The same strategy was used to knock in active kstd and $k s h$ genes. The kstd2 gene from Mycobacterium neoaurum DSM 1381 (Additional file 1: Figure S1) [44] was amplified by PCR using the primers KstD-OF and KstDOR (Additional file 1: Table S3). The amplified kstd2 fragment and the plasmid p2NIL-SacB with kstd upstream and downstream homology arms were treated with $X b a \mathrm{I}$ and digested products were purified with PCR clean-up kits. The digested $k s t d 2$ gene fragment and plasmid were ligated using T4 DNA ligase to obtain the KstD2 knockin vector. The ligation mixture was transformed into $E$. coli DH5a for amplification and DNA sequencing. The $k s h A$ knockin vector was constructed in the same manner as the above except for its template. A $k s h A$ gene was adopted from kshA51 (Additional file 1: Figure S2) [57] and chemically synthesized. The synthetic kshA51 gene was ligated with the plasmid p2NIL-SacB with $k s h A 226$ upstream and downstream homology arms to obtain the kshA51 knockin vector.

\section{Screening of recombinant mutants}

DNA electroporation was performed with a Gene Pulser Xcell System (BioRad, Hercules, CA, USA) according to a protocol described by Goude et al. [58]. The competent cells were prepared by the following procedure. The bacteria were cultured in $50 \mathrm{~mL}$ of LB medium containing $0.05 \%$ Tween- 80 until the $\mathrm{OD}_{600 \mathrm{~nm}}$ value reached 0.4 . The cells were collected by centrifugation and washed three times with $10 \%$ glycerol containing $0.05 \%$ Tween- 80 . Cell pellets were then resuspended in $100 \mu \mathrm{L}$ of $10 \%$ glycerol solution and used as competent cells. Then, $5 \mathrm{ng}$ of recombinant plasmid was added to $100 \mu \mathrm{L}$ of competent cells, and the mixture was transferred to a $0.2 \mathrm{~cm}$ precooled electroporation cuvette. A single pulse of $2.5 \mathrm{kV}$, $25 \mu \mathrm{F}$ and a resistance of $1000 \Omega$ with a constant wave pulse was usually used. The time constant was set for 23 ms. The bacterial suspension was diluted to $1 \mathrm{~mL}$ with $\mathrm{LB}$ medium and incubated for $3 \mathrm{~h}$ at $30{ }^{\circ} \mathrm{C}$. The culture was then spread on an LB agar plate containing $50 \mathrm{mg} /$ $\mathrm{ml}$ kanamycin (LBK) and allowed to grow at $30{ }^{\circ} \mathrm{C}$ for 3 days. Colonies were screened by PCR for positive recombination.

A few colonies growing on LBK plates were picked, and each colony was inoculated into $5 \mathrm{~mL}$ of LBT medium (0.05 Tween-80 in LB) containing $50 \mathrm{mg} / \mathrm{mL}$ of kanamycin and cultured at $30{ }^{\circ} \mathrm{C}$ and $200 \mathrm{rpm}$ for 2 days. The cell culture was diluted in $10^{3}$ - and $10^{5}$-fold with LBT medium. Then, $100 \mu \mathrm{L}$ of diluted cell suspension was spread on LBK agar plates containing $10 \%$ sucrose (LBKS), and $100 \mu \mathrm{L}$ of diluted cell suspension was also 
spread on LBK agar plates as a control. Both types of plates were incubated at $30^{\circ} \mathrm{C}$ for 3 days. When the number of colonies on the LBKS plates was less than that on the LBK plates, colonies were picked from the LBKS plates for PCR verification. Positive colonies were transferred to $5 \mathrm{~mL}$ of LBT medium and cultured at $30{ }^{\circ} \mathrm{C}$ and $200 \mathrm{rpm}$ for 2 days. Their genomic DNAs were extracted for PCR verification. The verified mutant strains were stored at $-80^{\circ} \mathrm{C}$.

\section{Small-scale fermentation}

The wild-type and mutant Mycobacterium strains were initially cultured in $5 \mathrm{~mL}$ of LB medium at $30^{\circ} \mathrm{C}$ for two or three days till its $\mathrm{OD}_{600 \mathrm{~nm}}$ value reached 13-15. The culture is used as seeds and was inoculated into a 100 $\mathrm{mL}$ of fermentation medium that contains yeast extract $(8 \mathrm{~g} / \mathrm{L})$, glycerol $(6 \mathrm{~g} / \mathrm{L}),\left(\mathrm{NH}_{4}\right)_{2} \mathrm{HPO}_{4}(0.6 \mathrm{~g} / \mathrm{L}), \mathrm{NaNO}_{3}$ $(2 \mathrm{~g} / \mathrm{L})$, phytosterol $(10 \mathrm{~g} / \mathrm{L}), \mathrm{F}-35(20 \mathrm{~g} / \mathrm{L}), \beta$-cyclodextrin $(5 \mathrm{~g} / \mathrm{L})$, and lectin $(3 \mathrm{~g} / \mathrm{L})$, and shaken at $30{ }^{\circ} \mathrm{C}$ and $200 \mathrm{rpm}$. Then, $1 \mathrm{ml}$ of fermentation broth was collected every $24 \mathrm{~h}$ for 7 days for the extraction of metabolites.

The fermentation broth was thoroughly mixed with ethyl acetate at a ratio of 1:1. The mixture was centrifuged at $8000 \times g$ for $5 \mathrm{~min}$ and the supernatant was collected. An aliquot of the supernatant was directly used for thin layer chromatographic (TLC) assay. The supernatant was collected and dried by heating using a hair drier. The dried sample was dissolved in $40 \%$ methanol solution for high-performance liquid chromatographic (HPLC) assays.

\section{Molecular cloning, expression and purification of KstD2 and KshA51 enzymes}

Preparation of KstD211 and KshA395 were described previously by Wang et al. [55]. The synthetic KstD2 and KshA51 genes were subcloned through BamH I and EcoR I into a modified pET28b vector that its thrombin cleavage site was replaced with a Tobacco Etch Virus (TEV) protease cleavage site. Each plasmid was individually transformed into E. coli BL21(DE3) cells for protein expression. Protein expression and purification of KstD2 and KshA51 enzymes were performed according to previously-reported procedure [55]. Purified KstD2 and KshA51 enzymes were assayed with SDS-PAGE as a single band and used for activity assay.

\section{3-Ketosteroid-1,2-dehydrogenase activity assay}

The activity of 3-ketosteroid-1,2-dehydrogenase (KstD) was measured spectrophotometrically at $600 \mathrm{~nm}$ for 10 min at $30{ }^{\circ} \mathrm{C}$ using 5-Methylphenazinium methosulfate (PMS) and 2,6-Dichlorophenolindphenol (DCPIP) as artificial electron acceptors. The reaction was conducted in $500 \mu \mathrm{L}$ of mixture solution containing $50 \mathrm{mM}$
Tris- $\mathrm{HCl}$ buffer (pH 7.0), $1.5 \mathrm{mM}$ PMS, $40 \mu \mathrm{M}$ DCPIP and $250 \mathrm{mM}$ AD in $2 \%$ methanol. The reaction was initiated by adding $20 \mu \mathrm{g}$ of purified KstD211 or KstD2. A reaction lacking $\mathrm{AD}$ was monitored as a control. Activity is expressed as $\mathrm{U} / \mathrm{mg}$ of protein after subtracting control data. One unit $(\mathrm{U})$ of enzyme activity is defined as the amount of enzyme required for reduction of $1 \mu \mathrm{mol}$ of DCPIP per minute $\left(\varepsilon_{600 \mathrm{~nm}}=18.7 \times 10^{3} \mathrm{~L} / \mathrm{mol} \cdot \mathrm{cm}\right)$.

\section{3-Ketosteroid-9a-hydroxylase activity assay}

The assay of 3-ketosteroid-9a-hydroxylase (Ksh) activity was performed by a method modified from a procedure published by Petrusma et al. [50]. Briefly, the reaction mixture contained $500 \mu \mathrm{L}$ of air-saturated 50 $\mathrm{mM}$ Tris-HCl buffer (pH 7.0), $100 \mu \mathrm{M}$ NADH and $20 \mu \mathrm{g}$ of enzyme. The reaction was initiated by the addition of $250 \mu \mathrm{M} 4-\mathrm{AD}$ into the mixture. The substrate solution was prepared by dissolving 4-AD powder in methanol. All assays were performed at $25^{\circ} \mathrm{C}$. A kinetic program on a NanoDrop C2000 spectrophotometer was used to continuously record NADH oxidation at $340 \mathrm{~nm}(\varepsilon=6.22 \mathrm{~L} /$ $\mathrm{mol} \mathrm{cm}$ ).

The enzymatic conversion of 4-AD to $9 \mathrm{OH}-\mathrm{AD}$ was also evaluated by monitoring substrate and product concentrations using an HPLC system equipped with a Waters $2945 \mathrm{UV}$ detector at $215 \mathrm{~nm}$ and a $150 \times 4.6 \mathrm{~mm}$ C18 reverse-phase $5 \mu \mathrm{m}$ ODS-analytical column. The mobile phase contained $40 \%$ methanol and $60 \%$ water and the flow rate was set at $1 \mathrm{ml} / \mathrm{min}$. In this work, the elution times for 4-AD and 9OH-AD were 10.6 and $4.4 \mathrm{~min}$, respectively. The concentrations of 4-AD and 9OH-AD were calculated from their respective peak areas using standard curves of 4-AD and $9 \mathrm{OH}-\mathrm{AD}$, respectively. The $R^{2}$ value for the standard curve was 0.99 .

\section{TLC and HPLC analyses of fermentation metabolites}

TLC assays were performed on 0.25 - $\mathrm{mm}$-thick silica gel that impregnated with fluorescent dye (Haiyang Chemical Co., Qingdao, China). Sample extracts were spotted in $5 \mu \mathrm{L}$ aliquots onto silica TLC plates. The TLC plates were developed with a solvent system containing petroleum ether and ethyl acetate at a ratio of $6: 4(\mathrm{v} / \mathrm{v})$ as the mobile phase. The products of the enzymatic reaction on TLC plates were visualized under ultraviolet (UV) light. If needed, the TLC plates were stained with $20 \%$ sulfuric acid at $100{ }^{\circ} \mathrm{C}$ for 10 min to identify compounds that were invisible under UV light.

HPLC analysis was carried out on a $C_{18}$ reverse-phase Sunfire column $(5 \mu \mathrm{m}, 4.6 \times 150 \mathrm{~mm}$, Waters, USA) at $30{ }^{\circ} \mathrm{C}$ with a Waters HPLC system equipped with a UV detector. Extracted metabolites dissolved in ethyl acetate were transferred to a clean glass vial and dried in vacuo. Dried powder was redissolved in methanol 
(approximately $1 \mathrm{mg} / \mathrm{mL}$ ), and the solution was then filtered through a $0.22 \mu \mathrm{m}$ microporous membrane. HPLC was performed using a mixture of methanol and water at a ratio of 60:40 (v/v) as the mobile phase at a flow rate of $1 \mathrm{~mL} / \mathrm{min}$. Analytes were detected with UV light at $214 \mathrm{~nm}$. The identities of HPLC peaks were confirmed by comparison with the standards of 4-AD, ADD, and $9 \mathrm{OH}-\mathrm{AD}$. Each peak area was integrated with software provided by Waters and used to evaluate the compound concentration.

The conversion rate (Conv) of phytosterol to 4-AD, $\mathrm{ADD}$ and $9 \mathrm{OH}-\mathrm{AD}$ was estimated using the following equation:

$$
\operatorname{Con} v=\frac{\frac{M s t}{M W s t}}{\left(\frac{M p}{M W p}\right)} \%,
$$

where $M_{s t}$ and $M p$ are the weights of steroid and phytosterol, respectively. $M W_{s t}$ and $M W p$ are the molecular weights of steroid and phytosterol, respectively. In this work, the average molecular weight of phytosterol is 410.40 Da (see above).

\section{Mass spectrometric analysis of fermentation metabolites}

LC/MS mass spectra of HPLC fractions were obtained under isocratic or gradient elution conditions, with acetonitrile:water $(1: 1)$ as the mobile phase. Small percentages of formic acid were added to the water mobile phase in some experiments to check the effects of the additives on the sensitivities and the mass spectra of the steroid compounds. After choosing the best conditions, i.e., acetonitrile:water $=60: 40$ with $0.2 \%$ formic acid, the detection limit was assessed for each fraction using selected ion monitoring of the most abundant ions in the spectra.

\section{Pilot-scale fermentation}

Pilot-scale fermentation was conducted in a $15 \mathrm{~L}$ fermenter. The fermentation medium consisted of yeast extract $(8 \mathrm{~g} / \mathrm{L})$, glycerol $(6 \mathrm{~g} / \mathrm{L}),\left(\mathrm{NH}_{4}\right)_{2} \mathrm{HPO}_{4}(0.6 \mathrm{~g} / \mathrm{L})$, $\mathrm{NaNO}_{3}(2 \mathrm{~g} / \mathrm{L})$, phytosterol $(80 \mathrm{~g} / \mathrm{L})$, F-35 (20 g/L), $\beta$-cyclodextrin $(20 \mathrm{~g} / \mathrm{L})$ and lectin $(3 \mathrm{~g} / \mathrm{L})$. Phytosterol was mixed with glycerol and $\beta$-cyclodextrin, and thoroughly emulsified before the mixture was transferred to the fermenter. All of the other materials were added into the fermenter, and water was added until the total volume of the medium reached $10 \mathrm{~L}$. The medium was autoclaved in situ at $121{ }^{\circ} \mathrm{C}$ for $30 \mathrm{~min}$, followed by cooling down to $30{ }^{\circ} \mathrm{C}$ with stirring at $500 \mathrm{rpm}$. The fermentation medium was inoculated with $1 \%(\mathrm{v} / \mathrm{v})$ of the seed that was cultured for 2 days. The fermentation was processed at $30{ }^{\circ} \mathrm{C}$ with stirring at $500 \mathrm{rpm}$ and the dissolved $\mathrm{O}_{2}$ concentration (50-60\%) and the $\mathrm{pH}$ value $(\mathrm{pH} 7.5)$ of the fermentation broth were constantly monitored in-line and automatically adjusted if necessary. Samples were collected every $6 \mathrm{~h}$ to monitor the concentration of 4-AD, ADD and 9OH-AD.

\section{Results}

\section{Characterization of HGMS2 fermentation extracts}

The wild-type HGSM2 strain has been used in the pharmaceutical industry to produce 4 - $\mathrm{AD}$ with a reasonable conversion rate and yield using phytosterol as a substate in an $80 \mathrm{~m}^{3}$ fermenter. A typical fermentation process was carried out for 7-10 days, during which time the process was monitored by TLC and HPLC assays until the substrates were completely converted. Figure 2a

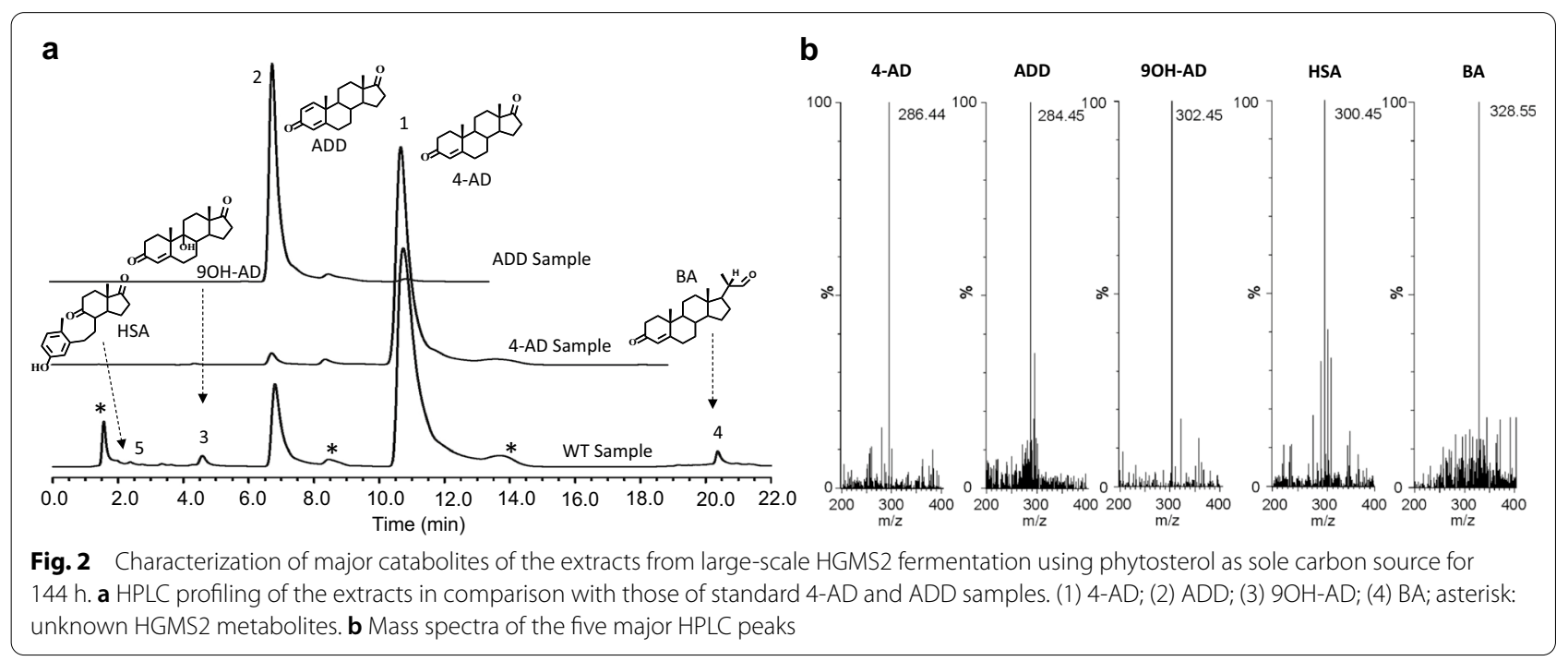


shows the HPLC profile of an extract from the HGMS2 fermentation broth after seven days of phytosterol fermentation. As shown in Fig. 2a, multiple products were accumulated during fermentation. Two major products were 4-AD and ADD, which were readily identified by comparison with the HPLC profiles of the standard 4-AD and ADD samples. Other minor peaks were identified as $9 \mathrm{OH}-\mathrm{AD}, \mathrm{HSA}$ and BA. All five products were further confirmed by mass spectrometry (Fig. 2b). Based on HPLC profiling, the contents of the five products were $78.21 \%, 10.33 \%, 1.43 \%, 3.85$ and $0.54 \%$ for $4-\mathrm{AD}, \mathrm{ADD}$, 9OH-AD BA and HSA, respectively, whereas the remaining contents were unknown metabolites unrelated to phytosterol catabolism.

\section{Construction of KstD-knockout and Ksh-knockout mutants} As indicated above, active KstD and Ksh enzymes diminished the accumulation of 4-AD via the formation of 9,10-secosteroid during phytosterol fermentation by the HGMS2 strain. Thus, we attempted to knock out these genes from the genome of the HGMS2 strain by homologous recombination approaches. To construct a homologous recombination vector with an appropriate antibiotic marker, we examined whether the HGMS2 strain had the ability to resist common antibiotics that can be deactivated by bacterial proteins. Although many mycobacterial species are resistant to a variety of antibiotics [59, 60], as shown in Additional file 1: Table S4, we found that the HGMS2 strain was not resistant to any tested antibiotics including kanamycin (Kan), tetracycline (Tc), streptomycin (Stm), spectinomycin (Spm), ampicillin (Amp) and zeocin $(\mathrm{Zn})$. Thus, we chose Kan as the first selection marker and the sucrose lethality gene $(\operatorname{SacB})$ [61] as the secondary selection marker to construct gene knockout/ knockin vectors. Using the p2NIL vector that contains a Kan gene as a template, we inserted a synthetic $S a c B$ gene into the p2NIL vector behind the Kan gene. The resultant vector was named p2NILSacB (Fig. 3a).

To use the pNILSac vector to knock out one kstd211 and three $k s h$ genes from the HGMS2 strain, each DNA fragment containing around $1000 \mathrm{bp}$ from both sides of a target gene was amplified with PCR and inserted into the BamH I and Hind III sites in the p2NILSac vector. Four recombinant vectors were constructed to delete the kstd211, kshA226, kshA395 and kshB122 genes from the HGMS2 genome and then confirmed by PCR (Additional file 1: Figure S3) and DNA sequencing. The four vectors were named p2NIL-SacB- $\Delta$ KstD211, p2NIL-SacB- $\Delta$ KshA226, p2NIL-SacB- $\Delta$ KshA395 and p2NILSacB- $\Delta$ KshB122 (Table 1).

Because ADD was a major by-product produced by active KstD211 enzyme during phytosterol fermentation with the wild-type HGMS2 strain, we knocked out the kstd211 gene from the HGMS2 genome in the first stage and then sequentially knocked out $k s h$ genes from the $k s t d$-knockout mutant. The knockout of the kstd211 gene was done by electroporation of the p2NIL-SacB- $\Delta$ KstD plasmid into fresh HGMS2 competent cells, followed by a two-step selection with kan- and sucrose-based methods (see "Materials and methods"). Positive recombinant colonies were identified with colony PCR. After the kstd211 gene was deleted from the HGMS2 genome, the size of the PCR product became much shorter (1600 bp) than that of the wild-type strain $(3600 \mathrm{bp})$. As shown in Fig. 3b, two positive colonies were identified, and DNA sequencing results confirmed that the kstd211 gene was knocked out from both clones. We arbitrarily selected one of these two colonies for further investigation and named it HGMS2 ${ }^{\Delta k s t d 211}$.

As mentioned above, the HGMS2 strain contains two pairs of KshA/KshB enzyme components sharing one single KshB enzyme. To explore the importance of individual Ksh enzymes in the formation of $9 \mathrm{OH}-\mathrm{AD}$, we knocked out each $k s h$ gene from the HGMS2 ${ }^{\Delta k s t d 211}$ mutant using the same knockout strategy that was used togenerate the HGMS2 $2^{\Delta k s t d 211}$ mutant. As shown in Fig. $3 \mathrm{c}$ and e, positive recombinant colonies were identified by colony PCR. DNA sequencing also confirmed that these $k s h$ genes were removed from the three colonies. The resultant mutants were named HGMS2 $2^{\Delta k s t d 211+\Delta k s h A 226}$, $\mathrm{HGMS}^{\Delta k s t d 211+\Delta k s h A 395}$ and HGMS2 ${ }^{\Delta k s t d 211+\Delta k s h B 122}$.

\section{Effect of KstD211 and Ksh enzymes on HGMS2 phytosterol transformation}

To evaluate the effects of kstd211 and ksh knockouts on phytosterol transformation in the HGMS2 strain, smallscale phytosterol fermentation was carried out for the HGMS2 strain and its knockout mutants. First, we tested the HGMS2 $2^{\Delta k s t d 211}$ mutant. After phytosterol fermentation for 7 days, the fermentation broth was extracted with a solvent and evaluated byTLC assay. As shown in Fig. 4a, the HGMS2 $2^{\Delta k s t d 211}$ mutant abolished ADD production compared with that of the WT strain. However, $9 \mathrm{OH}-\mathrm{AD}$ was detected on the TLC plate. Notably, knockout of the kstd211 gene slightly increased the conversion of 4-AD to 9OH-AD (Fig. 4a). Furthermore, the extract was diluted to the same concentration as that of the WT sample based on the TLC density and subjected to HPLC assay. As shown in Fig. 4b, knockout of the kstd211 gene caused the HGMS2 ${ }^{\Delta k s t d 211}$ strain to be almost free of ADD (peak 2 in Fig. 4b), and we once again observed that the yield of 9OH-AD increased (peak 3 in Fig. 4b). It was reasonable that the accumulation of $9 \mathrm{OH}-\mathrm{AD}$ occurred when the KstD211-involved formation of 9,10-secosteroid was blocked. 
a

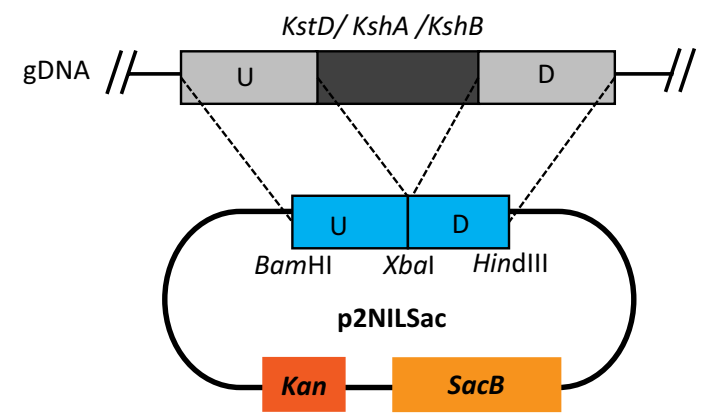

C

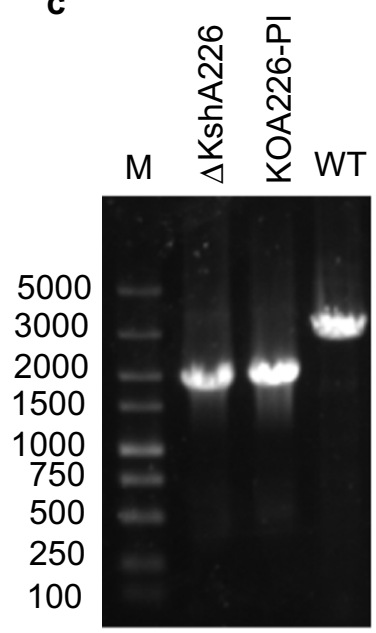

b

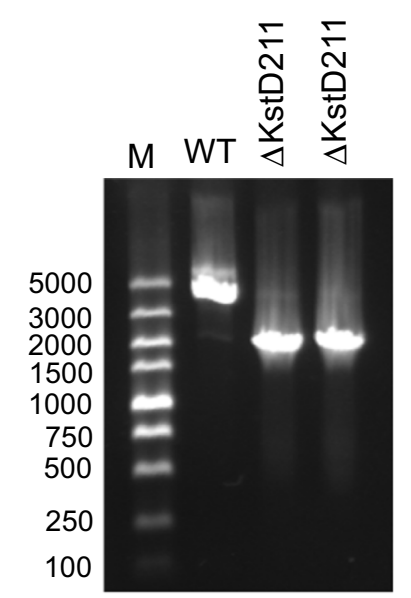

e
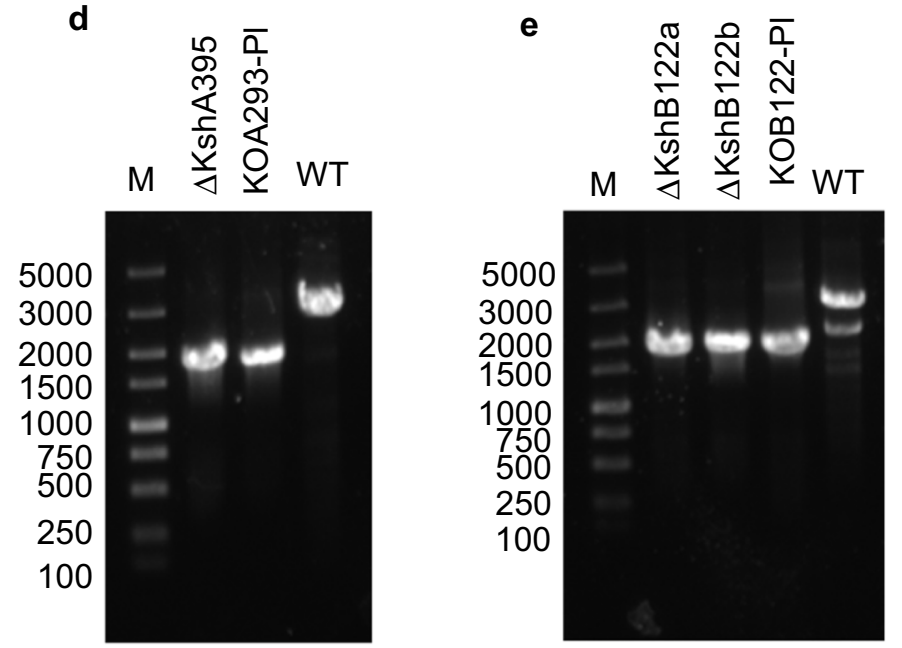

Fig. 3 Knockout of the kstd and ksh genes from the HGMS2 strain. a A homologous recombination vector was constructed based on p2NIL plasmid. U: the upstream sequence; D: the downstream sequence. b PCR confirmation of putative kstd-knockout colonies, in comparison with that for the WT strain. M: DNA marker; WT: PCR products amplified from the HGMS2; $\triangle$ KstD211: two putative kstd-default mutants. c-e PCR confirmation of putative ksh-knockout colonies, in comparison with that for the WT strain. M: DNA marker; $\triangle$ KshA226: a putative HGMS2 $2^{\triangle k s t D 211+\triangle k s h A 226}$ mutant; KOA226-PI: the plasmid p2NIL-Sac- $\triangle$ KshA226; WT: the HGMS2 strain; $\triangle$ KshA395: a putative HGMS2 ${ }^{\Delta k s t d 211+\Delta k s h A 395}$ mutant; KOA395-PI: the plasmid p2NIL-Sac- $\triangle$ KshA395; $\triangle$ KshB122a and $\triangle$ KshB122: two putative HGMS2 ${ }^{\Delta k s t d 211+\Delta k s h B 122}$ mutants; KOB122-PI: the plasmid p2NIL-Sac- $\Delta$ KshB122

Table 1 Lists of homologous recombinant knockout and knockin vectors

\begin{tabular}{|c|c|c|c|}
\hline Mutation & Vector & Targeted gene & Starting strain \\
\hline KO & p2NIL-SacB- $\triangle$ KstD211 & kstd211 & WT \\
\hline KO & p2NIL-Sacb- $\Delta$ KshA226 & kshA226 & HGMS2 $2^{\Delta k s t d 211}$ \\
\hline $\mathrm{KO}$ & p2NIL-SacB- $\triangle$ KshA395 & kshA395 & $\mathrm{HGMS} 2^{\Delta k s t d 211}$ \\
\hline KO & p2NIL-SacB- $\triangle$ KshB122 & kshB122 & HGMS2 $2^{\Delta k s t d 211}$ \\
\hline $\mathrm{Kl}$ & p2NIL-SacB-KstD2 & kstD211 & $\begin{array}{l}\mathrm{HGMS}_{\Delta \mathrm{kshB122}} 2^{\Delta k s t d 211} \\
\end{array}$ \\
\hline $\mathrm{Kl}$ & p2NIL-SacB-KshA51 & kshA226 & $\mathrm{HGMS} 2^{\Delta k s t d 211}$ \\
\hline
\end{tabular}

We further tested the effects of the three $k s h$ knockout mutants on phytosterol transformation on a small scale. As shown in Fig. 4a, knockout of the three ksh genes from the HGMS2 strain exerted a distinct effect on the accumulation of $9 \mathrm{OH}-\mathrm{AD}$. A weak spot was found for the sample from the HGMS2 $2^{\Delta k s t d 211+\Delta k s h A 226}$ mutant, while no detecTable $9 \mathrm{OH}-\mathrm{AD}$ spots were visualized for the other two mutants. This observation was consistent with our previous finding that KshA226 was inactive for 4-AD production, in contrast to KshA395 and KshB122 [55]. As shown in Fig. 4b, HPLC profiling of these extracts clearly indicated that the production of $9 \mathrm{OH}-\mathrm{AD}$ was completely blocked during phytosterol 


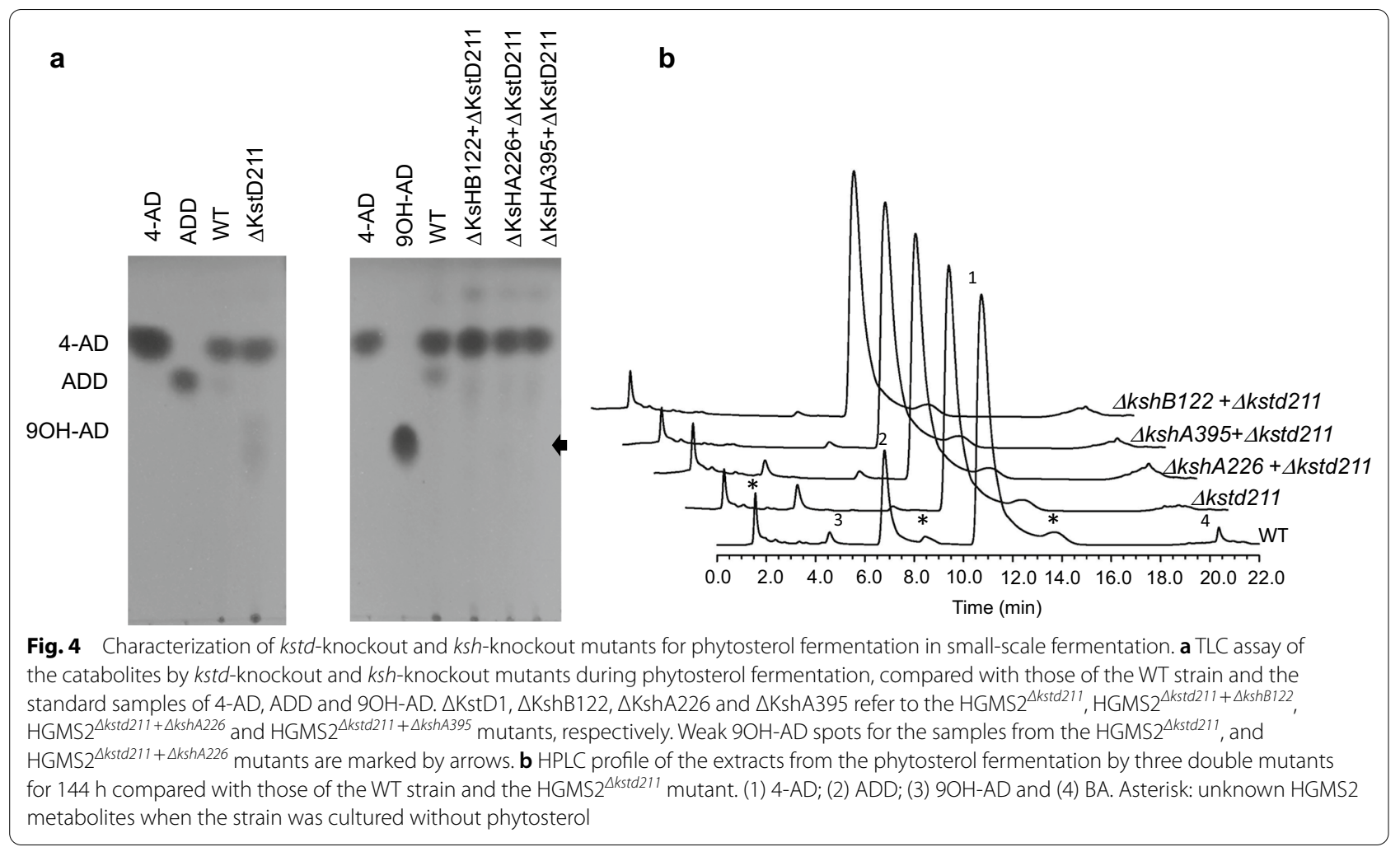

transformation in the HGMS2 $2^{\Delta k s t d 211+\Delta k s h A 395}$ and HGMS2 ${ }^{\Delta k s t d 211+\Delta k s h B 122}$ mutants. Notably, the production of ADD was also blocked in these two mutant strains. No detecTable $9 \mathrm{OH}-\mathrm{AD}$ was observed at the end of 7 days of fermentation and 4-AD significantly accumulated in the HGMS2 $2^{\Delta k s t d 1+\Delta k s h B 122}$ mutant with a conversion rate of $47.2 \%$ and a yield of $5.62 \mathrm{~g} / \mathrm{L}$ when starting from $10 \mathrm{~g} / \mathrm{L}$ of phytosterol (Table 2). Because the deletion of $k s h B 122$ could simultaneously disable the functions of the Ksh226 and KshA395 enzymes, we selected the HGMS2 $2^{\Delta k s t d 1+\Delta k s h B 122}$ mutant for pilot scale fermentation.

\section{Pilot-scale phytosterol fermentation} with the HGMS2 $2^{\Delta k t d 211+\Delta k s h B 122}$ mutant

Pilot-scale phytosterol fermentations using both the wild-type HGMS2 strain and the HGMS2 $2^{\Delta k t d 211+\Delta k s h B 122}$ mutant were conducted in a $15 \mathrm{~L}$ fermenter supplied with $10 \mathrm{~L}$ fermentation medium (see "Materials and methods").

As shown in Fig. 5a, the rate of phytosterol conversion to 4-AD increased dramatically within the first 5 days and reached $40.6 \%$ after 7 days of fermentation with $80 \mathrm{~g} / \mathrm{L}$ of phytosterol, while the phytosterol content in the medium decreased. On average, the final yield of 4-AD was $31.4 \pm 4.3 \mathrm{~g} / \mathrm{L}$ (Fig. 5b; Table 2). Accompanying the production of $4-\mathrm{AD}$ was the accumulation of ADD and $9 \mathrm{OH}-\mathrm{AD}$ also observed With yields of $6.26 \mathrm{~g} / \mathrm{L}$ and $0.88 \mathrm{~g} / \mathrm{L}$ on average (Table 2 ), respectively, after 7 days of fermentation (Fig. 5b), Resulting in total contents of 9.8 and $1.8 \%$ on average, respectively. (Fig. $5 \mathrm{a}$ ).

As expected, the HGMS2 $2^{\Delta k s t d 211+\Delta k s h B 122}$ mutant exhibited an enhanced conversion rate of phytosterol to 4-AD. As shown in Fig. $5 \mathrm{c}$, the rate of phytosterol conversion to $4-\mathrm{AD}$ increased to $48.7 \%$ after 7 days of fermentation. The final 4-AD yield in the fermentation broth was estimated to be $38.3 \pm 4.7 \mathrm{~g} / \mathrm{L}$ on average (Fig. $5 \mathrm{~d}$; Table 2), after transformation from $80 \mathrm{~g} / \mathrm{L}$ of phytosterol. Notably, ADD and 9OH-AD almost completely disappeared. When compared with the wild-type HGMS2 strain, the mutant strain enhanced the conversion rate and 4-AD yield by 1.2-fold and 1.2-fold, respectively. Moreover, the HGMS2 $2^{\Delta k s t d 211+\Delta k s h B 122}$ mutant completely catabolized the substrate with the same efficiency as the wild-type strain after 7 days of fermentation (Fig. 5).

\section{Construction of ADD-producing and 9OH-AD-producing mutants}

Encouraged by the performance of the HGMS2 $2^{\Delta k s t d 211+\Delta k s h B 122}$ mutant, we attempted to use $k s t d$ - and $k s h$-default mutants as cell models to construct an ADD-producing strain and a 9OH-ADproducing strain. The KstD2 from Mycobacterium neoaurum DSM 1381 is homologous to KstD211 and 
Table 2 Comparison of conversion rates and yields of 4-AD, ADD and 9OH-AD from phytosterol by a variety of Mycobacterium strains

\begin{tabular}{|c|c|c|c|c|c|c|}
\hline \multirow[t]{2}{*}{ Strain } & \multirow{2}{*}{$\begin{array}{l}\text { Phytosterol } \\
\text { concentration } \\
\text { (g/L) }\end{array}$} & \multicolumn{3}{|l|}{ Yield } & \multirow[t]{2}{*}{ Conversion rate } & \multirow[t]{2}{*}{ References } \\
\hline & & $4-A D(g / L)$ & $A D D(g / L)$ & $90 H-A D(g / L)$ & & \\
\hline \multicolumn{7}{|l|}{ 4-AD-producing strains } \\
\hline Mycobacterium sp. ATCC 25795 & 15 & 6.85 & 5.57 & N/A & $45.67 \%$ (4-AD); 37.13\% (ADD) & {$[64]$} \\
\hline Mycobacterium sp. B-3683 & 5 & 2.35 & N/A & N/A & $47 \%$ & {$[65]$} \\
\hline Mycobacterium sp. B-3805 & 20 & 7.4 & N/A & N/A & $37 \%$ & {$[51]$} \\
\hline Mycobacterium smegmatis MC 155 & 10 & $8.8-9.0$ & $1.0-1.1$ & N/A & N/A & {$[26]$} \\
\hline Mycobacterium sp. HGMS2 & 10 & 5.62 & 1.30 & 0.30 & $47.2 \%$ & This work \\
\hline Mycobacterium sp. HGMS2 & 80 & 31.4 & 6.26 & 0.88 & $40.6 \%$ & This work \\
\hline Mycobacterium sp. HGMS2 $2^{\Delta k s t d 211+\Delta k s h B 122}$ & 10 & 6.22 & NO & NO & $51.6 \%$ & This work \\
\hline Mycobacterium sp. HGMS2 $2^{\Delta k s t d 211+\Delta k s h B 122}$ & 80 & 38.3 & NO & NO & $48.7 \%$ & This work \\
\hline \multicolumn{7}{|l|}{ ADD-producing strains } \\
\hline Mycobacterium neoaurum NwIB-04 & 15 & 0.096 & 4.94 & N/A & $32.93 \%$ & {$[32]$} \\
\hline Mycobacterium neoaurum NwIB-01 & 0.4 & N/A & 0.174 & N/A & $43.5 \%$ & {$[31]$} \\
\hline Mycobacterium sp. HGMS2 $2^{k s t d 2+\Delta k s t d 211+\Delta k s h B 122}$ & 10 & NO & 4.12 & NO & $44.2 \%$ & This work \\
\hline Mycobacterium sp. HGMS2 $2^{k s t d 2+\Delta k s t d 211+\Delta k s h B 122}$ & 80 & NO & 34.2 & NO & $42.5 \%$ & This work \\
\hline \multicolumn{7}{|l|}{ 9OH-AD-producing strains } \\
\hline Mycobacterium sp. MS136 & 13 & N/A & N/A & 6.0 & $40 \%$ & {$[21]$} \\
\hline Mycobacterium neoaurum 25795 mutant & 20 & N/A & N/A & 10.27 & $51.2 \%$ & {$[63]$} \\
\hline Mycobacterium neoaurum ATCC 25795 mutant & 15 & N/A & N/A & 6.20 & $41.33 \%$ & {$[30]$} \\
\hline 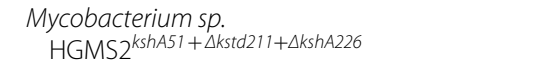 & 10 & NO & NO & 4.2 & $44.2 \%$ & This work \\
\hline 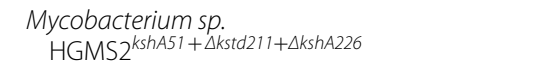 & 80 & NO & NO & 37.2 & $40.3 \%$ & This work \\
\hline
\end{tabular}

N/A data not available, $S D$ significant detectable, NO not observable

other KstD enzymes (Additional file 1: Figure S4). The activity of the KstD2 enzyme is much higher than that of the original KstD enzyme in the HGMS2 strain (i.e., KstD211 that converts 4-AD to ADD;Table 3). Therefore, we substituted the kstd211 gene in HGMS2 ${ }^{\Delta k s t d 1+\Delta k s h B 122}$ with the $k s t d 2$ gene to generate an ADD-producing mutant strain. This knockin mutant, which was confirmed by PCR (Additional file 1: Figure S5a) and DNA sequencing, was named HGMS2 ${ }^{k s t d 2+\Delta k s t d 211+\Delta k s h B 122}$ (Table 3). During tested in a small-scale fermentation system using phytosterol as substrate, the HGMS2 $2^{k s t d 2+\Delta k s t d 211+\Delta k s h B 122}$ mutant efficiently accumulated ADD within 7 days with a conversion rate of $44.2 \%$ and a yield of $4.12 \mathrm{~g} / \mathrm{L}$ starting from $10 \mathrm{~g} / \mathrm{L}$ of phytosterol (Table 2). Upon HPLC analysis (Fig. 6a), no detecTable 4-AD and 9OH-AD peaks were observed and all 4-AD generated in the HGMS2 $2^{\Delta k s t d 211+\Delta k s h B 122}$ mutant was eventually transformed to ADD in the HGMS2 $2^{k s t d 2}+\Delta k s t d 211+\Delta k s h B 122$ mutant. During pilot-scale fermentation, the conversion rate of phytosterol to ADD was $42.5 \%$ on average after 7 days of fermentation with $80 \mathrm{~g} / \mathrm{L}$ of phytosterol. The final ADD yield in the fermentation broth was estimated to be $34.2 \pm 5.3 \mathrm{~g} / \mathrm{L}$ on average (Fig. 6b; Table 2).
As shown in Fig. 6b, this ADD-producing mutant completely catabolized the substrate after 5.5 days during pilot-scale fermentation. In this process, $4-\mathrm{AD}$ was an intermediate, and its accumulation started to increase within the first 3.5 days, after which it decreased until complete transformation to ADD had occurred.

KshA51 is a chimeric KshA enzyme that is generated by KshA1 and KshA5 from $R$. rhodochrous DSM 43269 [57] and is homologous to KshA395 and other KshA enzymes (Additional file 1: Figure S6). KshA51 is much more active than KshA395 for 4-AD (Table 3). To construct a $9 \mathrm{OH}-\mathrm{AD}$-producing strain, we replaced the latent $k s h A 226$ gene in the HGMS2 ${ }^{\Delta k s t d 211+\Delta k s h A 226}$ mutant with a synthetic KshA51 gene that was knocked into the locus of $k s h A 226$ in the HGMS2 ${ }^{\Delta k s t d 211+\Delta k s h A 226}$ mutant. The resultant mutant was confirmed by PCR (Additional file 1: Figure S5b) and DNA sequencing and then named HGMS2 $2^{k s h A 51+\Delta k s t d 211+\Delta k s h A 226}$ (Table 3). We examined the HGMS2 $2^{k s h A 51+\Delta k s t d 211+\Delta k s h A 226}$ mutant for phytosterol transformation during small-scale fermentation for 7 days. The catabolites from the fermentation broth were extracted and evaluated by HPLC. As shown in Fig. 6a, no detecTable 4-AD or ADD was observed at the end of 7 days of fermentation, and 9OH-AD significantly 

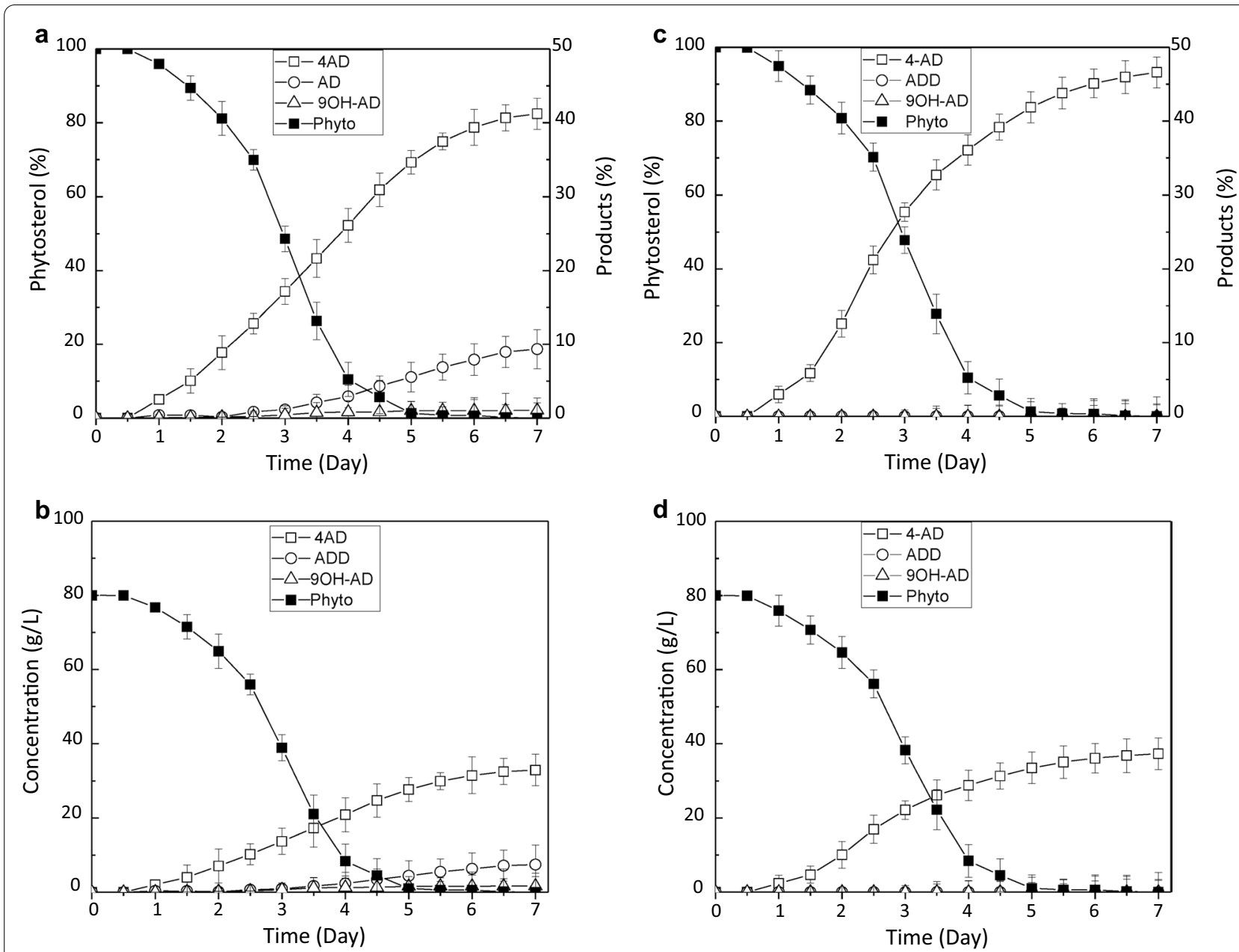

Fig. 5 Time course of phytosterol transformation to 4-AD, ADD and 9OH-AD in pilot-scale fermentation. $\mathbf{a}$, $\mathbf{b}$ The conversion rate and yield of phytosterol by the HGMS2 strain, compared with the wild-type strain.; c, b The conversion rate and yield of phytosterol by the HGMS2 $2^{\Delta k s t D 211+\Delta k s h B 122}$ mutant

Table 3 Construction of ADD- and 9OH-AD-producing mutants through knocking in highly-active kstd and ksh genes, respectively

\begin{tabular}{|c|c|c|c|c|c|c|}
\hline \multirow[t]{2}{*}{ Product } & \multirow[t]{2}{*}{ Starting strain } & \multicolumn{2}{|c|}{ Original gene } & \multirow[t]{2}{*}{ Mutant strain } & \multicolumn{2}{|c|}{ Knockin gene } \\
\hline & & Enzyme & $\begin{array}{l}\text { In vitro Activity } \\
\text { (units/mg) }\end{array}$ & & Enzyme & $\begin{array}{l}\text { In vitro } \\
\text { activity } \\
\text { (units/mg) }\end{array}$ \\
\hline $\mathrm{ADD}$ & $\mathrm{HGMS2} 2^{\Delta k s t k d 211+\Delta k s h B 122}$ & KstD211 & $125.7 \pm 23.4$ & $\mathrm{HGMS} 2^{\Delta k s t d 211+\Delta k s h B 122+k s t D 2}$ & KstD2 & $9238.7 \pm 68$ \\
\hline $9 O H-A D$ & $\mathrm{HGMS} 2^{\Delta k s t d 211+\Delta k s h 226}$ & KshA395 & $56.4 \pm 7.9$ & HGMS2 $2^{\Delta k s t d 211+\Delta k s h A 226+k s h A 51}$ & KshA51 & $532 \pm 42$ \\
\hline
\end{tabular}

accumulated in this mutant with a conversion rate of $44.2 \%$ and a yield of $4.2 \mathrm{~g} / \mathrm{L}$ when starting from $10 \mathrm{~g} / \mathrm{L}$ of phytosterol (Table 2). During a pilot-scale fermentation the conversion rate of phytosterol to $9 \mathrm{OH}-\mathrm{AD}$ was $40.3 \%$ on average after 7 days of fermentation (Fig. 6c). As shown in Fig. 6c; Table 2, this 9OH-AD-producing mutant completely catabolized the phytosterol substrate
(80 g/L) after 6 days, with an estimated final 9OH$\mathrm{AD}$ yield in the fermentation broth of $37.2 \pm 5.3 \mathrm{~g} / \mathrm{L}$ on average. During phytosterol transformation, 4-AD was an intermediate and its 4-AD accumulation started to increase within the first 3 days, after which it decreased until early completely transformation to $9 \mathrm{OH}-\mathrm{AD}$ had occurred. 


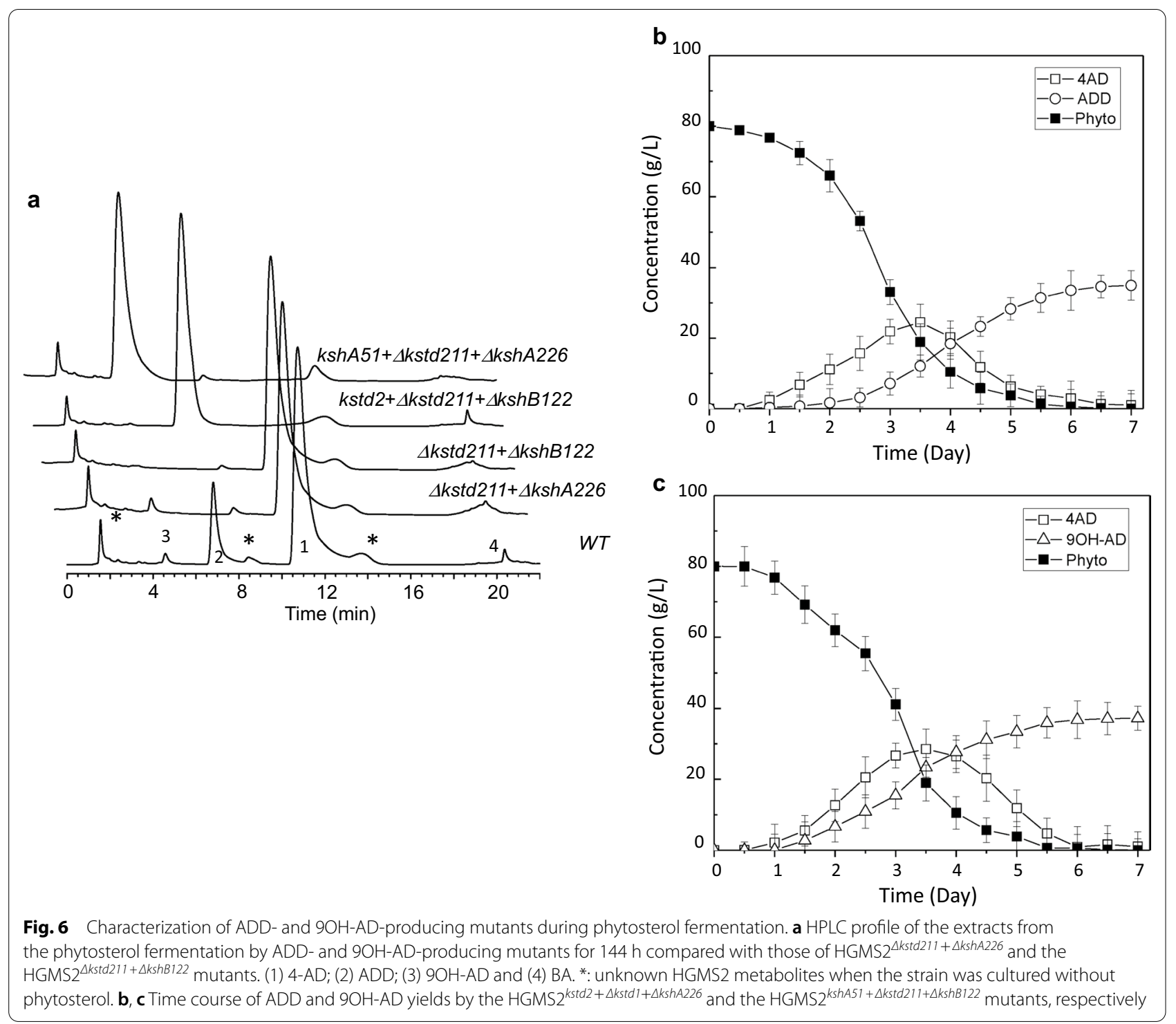

\section{Discussion}

Previously, many Mycobacteria and their kstd-knockout and/or ksh-knockout mutants were investigated for the accumulation of 4-AD, ADD and/or 9OH-AD. Many of these strains exhibited reasonable rates for the transformation of phytosterol with the potential for industrial application (Table 2). However, two major issues remained. Specifically, these Mycobacterium strains either continued to produce multiple products that hampered product purification or were investigated at lower concentrations of phytosterol. This indicated that it was likely that the template strains used in these pioneer works contained residual $k s t d$ and $k s h$ genes. Conversely, Mycobacterium neoaurum HGMS2 contained fewer kstd and ksh genes than other bacterial strains [26,
$31,43,52,62]$. In this study, we first generated a few $M$. neoaurum HGMS2 mutants by knocking out the kstd and $k s h$ genes. When compared with the wild-type strain, the mutants exhibited improved performance in the conversion of phytosterol to 4-AD. After the kstd211 gene was knocked out from the HGMS2 strain, the mutant HGMS2 ${ }^{4 k s t d 211}$ strain lost its ability to convert 4-AD to ADD; thus, ADD disappeared from the phytosterol fermentation broth. Furthermore, three $k s h$ genes were individually knocked out from the HGMS2 $2^{\Delta k s t d 211}$ mutant. The three double mutants that were exhibited different abilities to convert 4-AD to 9OH-AD. Specifically, the $\mathrm{HGMS}^{\Delta k s t d 211+\Delta k s h A 395}$ and $\mathrm{HGMS}^{\Delta k s t d 211+\Delta k s h B 122}$ mutants completely blocked the occurrence of $9 \mathrm{OH}-\mathrm{AD}$, while the HGMS2 ${ }^{\Delta k s t d 211+\Delta k s h A 226}$ mutant still converted 
4-AD to $9 \mathrm{OH}-\mathrm{AD}$. Therefore, knocking out the kstd gene first and then the $k s h$ genes benefited the accumulation of 4-AD during phytosterol conversion. Tested in pilotscale fermentation with a high concentration of phytosterol revealed that the HGMS2 ${ }^{\Delta k s t d 211+\Delta k s h B 122}$ mutant increased the conversion rate by 1.2 -fold to $48.7 \%$ on average. resulting in the 4-AD yield transformed by this double mutant increasing to $38.3 \pm 8.7 \mathrm{~g} / \mathrm{L}$. In our pilotscale fermentation, the conversion rate and 4-AD yield of our new 4-AD-producing strain only reached $75 \%$ of their theoretical values, i.e., $65 \%$ and $52.0 \mathrm{~g} / \mathrm{L}$, respectively. As shown in Figs. 2a and 6a, it was likely that the HGMS2 and its mutants still transformed phytosterol to $\mathrm{BA}$ and other intermediates. Further gene engineering should improve the 4-AD production yield. In our pilotscale study, we also observed that the viscosity of the fermentation broth increased significantly as the starting concentration of phytosterol increased from 10 to $80 \mathrm{~g} / \mathrm{L}$. Nevertheless, we did not observe any significant inhibitory growth by substrate or product (data not shown). Thus, we expect that it should be possible to increase the starting concentration of phytosterol in aqueous fermentation medium, when exploring new formulae for fermentation media.

Furthermore, we constructed ADD- and 9OH-ADproducing strains by knocking the genes of active heterogenous KstD and KshA enzymes into the $M$. neoaurum HGMS2 mutants, respectively. The resultant mutant HGMS2 ${ }^{k s t d 2+\Delta k s t d 211+\Delta k s h B 122}$ could efficiently and completely convert phytosterol to ADD with an average conversion rate of $42.5 \%$ and an average yield of $34.2 \pm 5.3 \mathrm{~g} / \mathrm{L}$ from $80 \mathrm{~g} / \mathrm{L}$ of phytosterol. The HGMS2 ${ }^{k s h A 51+\Delta k s t d 211+\Delta k s h A 226}$ mutants also efficiently converted phytosterol into $9 \mathrm{OH}-\mathrm{AD}$ with an average conversion rate of $40.3 \%$ and an average yield of $37.2 \pm 5.2 \mathrm{~g} / \mathrm{L}$ from $80 \mathrm{~g} / \mathrm{L}$ of phytosterol. These results were comparable to those obtained with other mycobacterial strains [21, 30, 31, 63]. One of the significant advantages of our mutants was that they generated less impurities. Because these two mutants were made of $k s t d$ - and $k s h$-knockout strains, further knock outs of other impurity-related genes should improve the ADD and $9 \mathrm{OH}-\mathrm{AD}$ production yield.

In conclusion, our work provides efficient mutants for the production of 4-AD, ADD and 9OH-AD for industrial application. The gene implementation of $M$. sp. HGMS2 in this work has demonstrated that the HGMS2 strain is an excellent model for engineering microbial cell factories to produce important steroidal compounds. The production of another important pharmaceutical compound, BA, via similar gene engineering methods is currently under investigation in our laboratory.
Abbreviations

4-AD: 4-Androstene-3,17-dione; 9OH-AD: 9a-Hydroxyl-4-androstene-3,17dione; ADD: 1,4-Androstene-3,17-dione; BA: 21-Hydroxy-20-methylpregn-4en-3-one; DCPIP: 2,6-Dichlorophenolindophenol; HPLC: High-performance liquid chromatography; HSA: 3-Hydroxy-9,10-secoandrost-1,3,5(10)-triene9,17-dione; KstD: 3-Ketosteroid-1,2-dehydrogenase; Ksh: 3-Ketosteroid-9ahydroxylase; TLC: Thin layer chromatography.

\section{Supplementary Information}

The online version contains supplementary material available at https://doi. org/10.1186/s12934-021-01653-9.

Additional file 1. Supplementary informations include homologous recombinant sequences for knocking out targeted genes in the HGMS2 mutants, primers used for the construction of knockout and knockin vectors, antibiotic resistances of the HGMS2 strain, DNA sequence of KstD2 gene, DNA sequence of KshA51 gene, amino acid alignment of KstD211 with other KstD enzymes, amino acid alignment of KshA51 with the Ksh enzymes from the HGMS2 strain, and experimental data for PCR screening of $\mathrm{KO}$ and $\mathrm{KI}$ mutants.

\section{Acknowledgements}

We thank Mr. Fangxin Lu for his technical assistance and Rita Su from the University of Toronto for language editing.

\section{Authors' contributions}

ZDS, YJH and YQH conceived and designed research. XL, TC, FP, SKS, JPY, DNS and XYC conducted experiments. XL, FP, SKS and JPY analyzed data. ZDS, $X \mathrm{~L}$ and $\mathrm{YQH}$ wrote the manuscript. All authors read and approved the manuscript.

\section{Funding}

The Hubei Provincial Ministry of Technology (ZDS, No: 2016ACA128), Natural Science Foundation of Hubei Province (Grant Number 2019CFB713) and National "111"Center for Cellular Regulation and Molecular Pharmaceutics (grant XBTK-2018001).

Availability of data and materials Not applicable.

\section{Declarations}

Ethics approval and consent to participate Not applicable.

Consent for publication

Not applicable.

Conflict of interest

The authors declare that they have no conflict of interest.

Received: 24 April 2021 Accepted: 9 August 2021

Published online: 16 August 2021

\section{References}

1. Donova MV, Egorova OV. Microbial steroid transformations: current state and prospects. Appl Microbiol Biotechnol. 2012;94:1423-47.

2. Shtratnikova VY, Schelkunov MI, Pekov YA, Fokina WV, Logacheva MD, Sokolov SL, Bragin EY, Ashapkin W, Donova MV. Complete genome sequence of steroid-transforming nocardioides simplex VKM Ac-2033D. Genome Announc. 2015;3:e01406-14.

3. Fernández-Cabezón L, Galán B, García JL. New insights on steroid biotechnology. Front Microbiol. 2018;9:15.

4. Donova MV. Steroid bioconversions. Methods Mol Biol. 2017;1645:1-13. 
5. Fernandes P, Cruz A, Angelova B, Pinheiro HM, Cabral JMS. Microbial conversion of steroid compounds: recent developments. Enzyme Microb Technol. 2003;32:688-705.

6. Donova MV. Transformation of steroids by actinobacteria: a review. App Biochem Microbiol. 2007:43:1-14.

7. Owen RW, Mason AN, Bilton RF. The degradation of beta-sitosterol by Pseudomonas sp. NCIB 10590 under aerobic conditions. J Steroid Biochem. 1985;23:327-32.

8. Shtratnikova VY, Schelkunov MI, Fokina W, Pekov YA, Ivashina T, Donova MV. Genome-wide bioinformatics analysis of steroid metabolismassociated genes in Nocardioides simplex VKM Ac-2033D. Curr Genet. 2016:62:643-56

9. Wei JH, Yin X, Welander PV. Sterol synthesis in diverse bacteria. Front Microbiol. 2016;7:19.

10. Wei W, Fan S, Wang F, Wei D. A new steroid-transforming strain of Mycobacterium neoaurum and cloning of 3-ketosteroid 9alpha-hydroxylase in NwIB-01. Appl Biochem Biotechnol. 2010;162:1446-56.

11. Marsheck WJ, Kraychy S, Muir RD. Microbial degradation of sterols. Appl Microbiol. 1972;23:72-7

12. Goren T, Harni M, Rimonk S, Aharonowitz Y. 1-Ene-steroid reductase of Mycobacterium SP. NRRL B-3805. J Steroid Biochem. 1983;19:1789-97.

13. Holert J, Cardenas E, Bergstrand LH, Zaikova E, Hahn AS, Hallam SJ, Mohn WW. Metagenomes reveal global distribution of bacterial steroid catabolism in natural, engineered, and host environments. mBio. 2018:9:e02345-02317.

14. Bergstrand LH, Cardenas E, Holert J, Van Hamme JD, Mohn WW. Delineation of steroid-degrading microorganisms through comparative genomic analysis. MBio. 2016;7:e00166.

15. Fujimoto Y, Chen CS, Szeleczky Z, Ditullio D, Sih CJ. Microbial degradation of the phytosterol side chain. I. Enzymic conversion of 3-oxo-24-ethylcholest-4-en-26-oic acid into 3-oxochol-4-en-24-oic acid and androst-4ene-3,17-dione. J Am Chem Soc. 1982;104:4718-20.

16. Malaviya A, Gomes J. Androstenedione production by biotransformation of phytosterols. Bioresour Technol. 2008;99:6725-37.

17. Kreit J. Microbial catabolism of sterols: focus on the enzymes that transform the sterol 3beta-hydroxy-5-en into 3-keto-4-en. FEMS Microbiol Lett. 2017;364:fnx007.

18. Chiang Y-R, Wei ST-S, Wang P-H, Wu P-H, Yu C-P. Microbial degradation of steroid sex hormones: implications for environmental and ecological studies. Microb Biotechnol. 2020;13:926-49.

19. Kreit J. Aerobic catabolism of sterols by microorganisms: key enzymes that open the 3-ketosteroid nucleus. FEMS Microbiol Lett. 2019;366:fnz173.

20. Li H, Wang X, Zhou L, Ma Y, Yuan W, Zhang X, Shi J, Xu Z. Enhancing expression of 3-ketosteroid-9a-hydroxylase oxygenase, an enzyme with broad substrate range and high hydroxylation ability, in Mycobacterium sp. LY-1. Appl Biochem Biotechnol. 2019;187:1238-54.

21. He K, Sun $H$, Song $H$. Engineering phytosterol transport system in Mycobacterium sp. strain MS136 enhances production of 9a-hydroxy-4androstene-3,17-dione. Biotech Lett. 2018;40:673-8.

22. Shao M, Sha Z, Zhang X, Rao Z, Xu M, Yang T, Xu Z, Yang S. Efficient androst-1,4-diene-3,17-dione production by co-expressing 3-ketosteroid$\triangle 1$-dehydrogenase and catalase in Bacillus subtilis. J Appl Microbiol. 2017;122:119-28.

23. Liu HH, Xu LQ, Yao K, Xiong LB, Tao XY, Liu M, Wang FQ, Wei DZ. Engineered 3-ketosteroid 9alpha-hydroxylases in emopenMycobacterium neoaurumemclose: an efficient platform for production of steroid drugs. Appl Environ Microbiol. 2018;84:e02777-17.

24. Yuan S-F, Alper HS. Metabolic engineering of microbial cell factories for production of nutraceuticals. Microb Cell Fact. 2019;18:46.

25. García-Fernández J, Martínez I, Fernández-Cabezón L, Felpeto-Santero C García J-L, Galán B. Bioconversion of phytosterols into androstadienedione by Mycobacterium smegmatis CECT 8331. Methods Mol Biol (Clifton NJ). 2017;1645:211-25.

26. Galán B, Uhía I, García-Fernández E, Martínez I, Bahílo E, de la Fuente JL, Barredo JL, Fernández-Cabezón L, García JL. Mycobacterium smegmatis is a suitable cell factory for the production of steroidic synthons. Microb Biotechnol. 2017;10:138-50.

27. Wang X, Feng J, Zhang D, Wu Q, Zhu D, Ma Y. Characterization of new recombinant 3-ketosteroid- $\triangle 1$-dehydrogenases for the biotransformation of steroids. Appl Microbiol Biotechnol. 2017;101:6049-60.
28. Shao M, Zhang X, Rao Z, Xu M, Yang T, Li H, Xu Z, Yang S. A mutant form of 3-ketosteroid-Delta(1)-dehydrogenase gives altered androst-1,4-diene-3, 17-dione/androst-4-ene-3,17-dione molar ratios in steroid biotransformations by Mycobacterium neoaurum ST-095. J Ind Microbiol Biotechnol. 2016:43:691-701.

29. Xie R, Shen Y, Qin N, Wang Y, Su L, Wang M. Genetic differences in ksdD influence on the ADD/AD ratio of Mycobacterium neoaurum. J Ind Microbiol Biotechnol. 2015;42:507-13.

30. Yao K, Xu L-Q, Wang F-Q, Wei D-Z. Characterization and engineering of 3-ketosteroid- $\triangle$ 1-dehydrogenase and 3-ketosteroid-9a-hydroxylase in Mycobacterium neoaurum ATCC 25795 to produce 9a-hydroxy-4androstene-3,17-dione through the catabolism of sterols. Metab Eng. 2014;24:181-91.

31. Wei W, Fan S-Y, Wang F-Q, Wei D-Z. Accumulation of androstadiene-dione by overexpression of heterologous 3-ketosteroid $\triangle 1$-dehydrogenase in Mycobacterium neoaurum NwIB-01. World J Microbiol Biotechnol. 2014;30:1947-54

32. Wei W, Wang F-Q, Fan S-Y, Wei D-Z. Inactivation and augmentation of the primary 3-ketosteroid-\{delta\}1- dehydrogenase in Mycobacterium neoaurum NwIB-01: biotransformation of soybean phytosterols to 4-androstene- 3,17-dione or 1,4-androstadiene-3,17-dione. Appl Environ Microbiol. 2010;76:578-4582.

33. Seidel $L$, Horhold C. Selection and characterization of new microorganisms for the manufacture of 9-OH-AD from sterols. J Basic Microbiol. 1992;32:49-55.

34. Rodina NV, Molchanova MA, Voishvillo NE, Andryushina VA, Stytsenko TS. Conversion of phytosterols into androstenedione by Mycobacterium neoaurum. Appl Biochem Microbiol. 2008;44:48-54.

35. Su L, Shen Y, Xia M, Shang Z, Xu S, An X, Wang M. Overexpression of cytochrome p450 125 in Mycobacterium: a rational strategy in the promotion of phytosterol biotransformation. J Ind Microbiol Biotechnol. 2018;45:857-67.

36. Su L, Shen Y, Zhang W, Gao T, Shang Z, Wang M. Cofactor engineering to regulate $\mathrm{NAD}(+) / \mathrm{NADH}$ ratio with its application to phytosterols biotransformation. Microb Cell Fact. 2017;16:182.

37. van der Geize R, Hessels Gl, van Gerwen R, van der Meijden P, Dijkhuizen L. Unmarked gene deletion mutagenesis of kstD, encoding 3-ketosteroid $\Delta 1$-dehydrogenase, in Rhodococcus erythropolis SQ1 using sacB as counter-selectable marker. FEMS Microbiol Lett. 2001;205:197-202.

38. van der Geize R, Hessels Gl, van Gerwen R, Vrijbloed JW, van der Meijden P, Dijkhuizen L. Targeted disruption of the kstD gene encoding a 3-ketosteroid delta 1-dehydrogenase isoenzyme of Rhodococcus erythropolis strain SQ1. Appl Environ Microbiol. 2000;66:2029-36.

39. Petrusma M, van der Geize R, Dijkhuizen L. 3-Ketosteroid 9alpha-hydroxylase enzymes: rieske non-heme monooxygenases essential for bacterial steroid degradation. Antonie Van Leeuwenhoek. 2014;106:157-72.

40. Ruprecht A, Maddox J, Stirling AJ, Visaggio N, Seah SY. Characterization of novel acyl coenzyme A dehydrogenases involved in bacterial steroid degradation. J Bacteriol. 2015;197:1360-7.

41. Rohman A, Dijkstra BW. The role and mechanism of microbial 3-ketosteroid $\Delta 1$-dehydrogenases in steroid breakdown. J Steroid Biochem Mol Biol. 2019;191:105366

42. Guevara G, Heras LFdl, Perera J, Llorens JMN. Functional characterization of 3-ketosteroid 9a-hydroxylases in Rhodococcus ruber strain chol-4. J Steroid Biochem Mol Biol. 2017;172:176-87.

43. Zhang R, Liu X, Wang Y, Han Y, Sun J, Shi J, Zhang B. Identification, function, and application of 3-ketosteroid $\triangle 1$-dehydrogenase isozymes in Mycobacterium neoaurum DSM 1381 for the production of steroidic synthons. Microb Cell Fact. 2018;17:77.

44. Zhang R, Xu X, Cao H, Yuan C, Yuminaga Y, Zhao S, Shi J, Zhang B. Purification, characterization, and application of a high activity 3-ketosteroidDelta(1)-dehydrogenase from Mycobacterium neoaurum DSM 1381. Appl Microbiol Biotechnol. 2019;103:6605-16.

45. Zhang Q, Ren Y, He J, Cheng S, Yuan J, Ge F, Li W, Zhang Y, Xie G. Multiplicity of 3-ketosteroid $\triangle 1$-dehydrogenase enzymes in Gordonia neofelifaecis NRRL B-59395 with preferences for different steroids. Ann Microbiol. 2015;65:1961-71

46. Szaleniec M, Wojtkiewicz AM, Bernhardt R, Borowski T, Donova M. Bacterial steroid hydroxylases: enzyme classes, their functions and comparison of their catalytic mechanisms. Appl Microbiol Biotechnol. 2018;102:8153-71. 
47. Bragin EY, Shtratnikova VY, Schelkunov MI, Dovbnya DV, Donova MV. Genome-wide response on phytosterol in 9-hydroxyandrostenedioneproducing strain of Mycobacterium sp. VKM Ac-1817D. BMC Biotechnol. 2019;19:39-9.

48. Penfield JS, Worrall $\sqcup$, Strynadka NC, Eltis LD. Substrate specificities and conformational flexibility of 3-ketosteroid 9alpha-hydroxylases. J Biol Chem. 2014;289:25523-36.

49. Petrusma M, Hessels G, Dijkhuizen L, van der Geize R. Multiplicity of 3-Ketosteroid-9alpha-Hydroxylase enzymes in Rhodococcus rhodochrous DSM43269 for specific degradation of different classes of steroids. J Bacteriol. 2011;193:3931-40.

50. Petrusma M, Dijkhuizen L, van der Geize R. Rhodococcus rhodochrous DSM 43269 3-ketosteroid 9a-hydroxylase, a two-component iron-sulfurcontaining monooxygenase with subtle steroid substrate specificity. Appl Environ Microbiol. 2009;75:5300-7.

51. Mancilla RA, Little C, Amoroso A. Efficient bioconversion of high concentration phytosterol microdispersion to 4-androstene-3,17-dione (AD) by Mycobacterium sp. B3805. Appl Biochem Biotechnol. 2018;185:494-506.

52. Shao M, Zhang X, Rao Z, Xu M, Yang T, Li H, Xu Z. Enhanced production of androst-1,4-diene-3,17-dione by Mycobacterium neoaurum JC-12 using three-stage fermentation strategy. PLoS ONE. 2015;10:e0137658.

53. Kim P-Y, Pollard DJ, Woodley JM. Substrate supply for effective biocatalysis. Biotechnol Prog. 2007;23:74-82.

54. Zhang X, Liu Y, Li H, Su L, Zhou L, Peng J, Shen R, Zhang Y, Shi J, Xu Z. Microemulsion system for Colletotrichum lini ST-1 biotransformation of dehydroepiandrosterone to 7a,15a-diOH-DHEA. Biochem Eng J. 2018;131:77-83.

55. Wang H, Song S, Peng F, Yang F, Chen T, Li X, Cheng X, He Y, Huang Y, Su Z. Whole-genome and enzymatic analyses of an androstenedione-producing Mycobacterium strain with residual phytosterol-degrading pathways. Microb Cell Fact. 2020;19:187.

56. Parish T, Stoker NG. Use of a flexible cassette method to generate a double unmarked Mycobacterium tuberculosis tlyA plcABC mutant by gene replacement. Microbiology. 2000;146:1969-75.
57. Petrusma M, Dijkhuizen L, van der Geize R. Structural features in the ksha terminal oxygenase protein that determine substrate preference of 3-ketosteroid 9a-hydroxylase enzymes. J Bacteriol. 2012;194:115-21.

58. Goude R, Parish T. Electroporation of Mycobacteria. In: Parish T, Brown AC, editors. Mycobacteria protocols. 2nd ed. Totowa: Humana Press; 2009. p. 203-15.

59. Gygli SM, Borrell S, Trauner A, Gagneux S. Antimicrobial resistance in Mycobacterium tuberculosis: mechanistic and evolutionary perspectives. FEMS Microbiol Rev. 2017;41:354-73.

60. Nguyen L, Thompson CJ. Foundations of antibiotic resistance in bacterial physiology: the mycobacterial paradigm. Trends Microbiol. 2006;14:304-12.

61. Borgers K, Vandewalle K, Festjens N, Callewaert N. A guide to Mycobacterium mutagenesis. FEBS J. 2019;286:3757-74.

62. Li Q, Ge F, Tan Y, Zhang G, Li W. Genome-wide transcriptome profiling of Mycobacterium smegmatis MC(2) 155 cultivated in minimal media supplemented with cholesterol, androstenedione or glycerol. Int J Mol Sci. 2016;17:689.

63. Xiong LB, Liu HH, Xu LQ, Wei DZ, Wang FQ. Role identification and application of SigD in the transformation of soybean phytosterol to 9alpha-hydroxy-4-androstene-3,17-dione in Mycobacterium neoaurum. J Agric Food Chem. 2017;65:626-31.

64. Yao K, Wang F-Q, Zhang H-C, Wei D-Z. Identification and engineering of cholesterol oxidases involved in the initial step of sterols catabolism in Mycobacterium neoaurum. Metab Eng. 2013;15:75-87.

65. Yuan J-J, Guan Y-X, Yao S-J. Evaluation of biocompatible ionic liquids for their application in phytosterols bioconversion by Mycobacterium sp. resting cells. ACS Sustain Chem Eng. 2017;5:10702-9.

\section{Publisher's Note}

Springer Nature remains neutral with regard to jurisdictional claims in published maps and institutional affiliations.
Ready to submit your research? Choose BMC and benefit from:

- fast, convenient online submission

- thorough peer review by experienced researchers in your field

- rapid publication on acceptance

- support for research data, including large and complex data types

- gold Open Access which fosters wider collaboration and increased citations

- maximum visibility for your research: over 100M website views per year

At BMC, research is always in progress.

Learn more biomedcentral.com/submissions 